\title{
Undergraduate Nursing Students’ Experience in Studying Evidence-Based Practice by Application of Concept Map
}

\author{
Amel I. Ahmed, Rasha A. Mohamed* \\ Community Health Nursing Department, Faculty of Nursing, Mansoura University, Egypt \\ *Corresponding author: drrashaabbas238@gmail.com \\ Received March 04, 2019; Revised April 18, 2019; Accepted May 13, 2019
}

\begin{abstract}
Background: Nowadays nurses should be competent in using knowledge in clinical decision-making for nursing intervention. Therefore, the application of evidence-based practice (EBP) in community healthcare settings is a crucial need that fortifies the quality of the provided services. The governmental policies mandate the application of EBP in healthcare services. The lack of EBP competencies among healthcare professionals including nurses is a barrier for achieving this mandate. Incorporating EBP in nursing curricula combined with interactive teaching strategy such as concept map would overcome this barrier. Aim: The study aimed at providing an overview of the experiences of undergraduate nursing students about studying evidence-based practice by the application of concept map as an educational strategy. Research Design: Qualitative phenomenology study design was used. Setting: The study was carried out at the faculty of nursing, Mansoura University, Egypt during the period from October 2018 until January 2019. Subjects and Sampling: Purposive sampling technique was used to recruit the study participants who were composed of 95 undergraduate nursing students registered at the courses of Community Health Nursing Department. Data collection: Focus group discussion (FGD) was used to collect the required data to achieve the aim of this study. Results: Undergraduate nursing students showed positive views regarding EBP and concept map. They showed interests in studying EBP and applying it in their future career. Nursing students were enthusiastic to use concept map in studying other courses because it helped them in understanding the course content and increased retaining of information. They found the concept map was very helpful in problem-solving. Conclusion and Recommendations: Teaching EBP by using concept map was accepted by undergraduate nursing students. The study recommended the continuity of teaching EBP for undergraduate nursing students and embedding the course of EBP in nursing curricula in post-graduate studies. Concept map would be used in teaching all nursing academic courses.
\end{abstract}

Keywords: concept map, evidence-based practice, nursing, teaching

Cite This Article: Amel I. Ahmed, and Rasha A. Mohamed, “Undergraduate Nursing Students’ Experience in Studying Evidence-Based Practice by Application of Concept Map.” American Journal of Nursing Research, vol. 7, no. 4 (2019): 437-444. doi: 10.12691/ajnr-7-4-5.

\section{Introduction}

Nursing organizations all over the world have been recognizing the importance of adopting evidence-based practice (EBP) to ensure the high quality of nursing interventions. Nurses should be competent in transforming knowledge into practice by demonstrating proficiency of EBP $[1,2,3]$. Application of EBP in community healthcare settings is well documented to strengthen the quality of the provided care. The effectiveness of different community health programs depend on an evidence-based clinical decision. The Egyptian accreditation standards of healthcare settings including primary healthcare centers require adopting evidence-based guidelines for managing different health conditions and infection control measures $[4,5]$. While the policies indicate the necessities of the application of EBP in healthcare services, nurses and other healthcare professionals reported barriers to this demand. Although the reported positive perception of nurses including community health nurses toward EBP, insufficient competency about EBP knowledge and skills is challenging them from translating EBP into different healthcare applications [6,7].

In response to the heightened importance of EBP in healthcare settings, nursing education institutions have the responsibility to prepare nursing students in terms of EBP mastery [8]. Integrating EBP into formal curriculum is the predominantly step to prepare nursing students for their professional role and attaining future practice needs $[9,10,11]$. Therefore, nursing academic institutions have been including EBP in both undergraduate and graduate nursing education curricula [12,13].

Teaching EBP at the undergraduate level requires interactive educational strategies that create an enjoyable 
teaching environment that which promotes students' learning process $[10,14,15]$. Concept mapping is one of the educational methods that actively engage students in educational activities and helps in acquiring critical thinking abilities $[16,17,18,19]$. Using of concept map enables students to make a decision in a complex and diverse healthcare environment as defined in different medical, nursing and public health literature [20,21,22,23].

Concept maps are a type of graphic illustration that shows how different concepts relate to each other. They are made of nodes (concept squares) and links (lines with tags) which are intended to represent knowledge and are used in a wide range of activities to make learning easier $[24,25]$. They can construct a schema of related concepts around a domain or clinical problem to foster clinical reasoning for effective patient care [26]. They may be conducted individually, or in groups. Individually developed concept maps permit students to discover important concepts and relations on their own time and terms. Collaborative mapping involves building or sharing concept maps as a group. Students can act together, transfer, and exchange opinions with other members of their group [27].

Few studies have specifically delineated student nurses' perceptions of EBP and its effective educational strategies [28]. More qualitative research is required to investigate the interactive educational strategies to improve the competencies of the undergraduate nursing students in skills of EBP [15]. Therefore, the current study was conducted to reflect the experiences of undergraduate nursing students about studying evidence-based practice and the application of the concept map in educating the course. The aim of this study was investigated through a qualitative study design.

\subsection{Aim of the Study}

The study aimed at providing an overview of the experiences of undergraduate nursing students about studying evidence-based practice by the application of concept map as an educational strategy.

The research questions were:

- What are the views of the nursing students about studying evidence-based practice?

- What are the skills that were acquired from studying evidence-based practice?

- What are the challenges faced nursing students in studying evidence-based nursing course?

- Do the nursing students accept the concept map as an educational method?

\section{Method}

\subsection{Study Design}

A qualitative phenomenology study design was used to achieve the aim of this study by using focus group discussion (FGD). According to Barbour, R. S. [29], the FGD is appropriate to draw-out the voice of students in relation to the introduction of a new educational method. The qualitative study design was used throughout this study to investigate in-depth the views and acceptability of students in relation to the newly introduced topic (Evidence-Based Practice) and educational method (Concept Map). Accordingly, a further modification for course sustainability would be established [30].

\subsection{Setting}

This study was carried out at the faculty of nursing, Mansoura University, Egypt.

\subsection{Sampling Size and Technique}

A convenience sample of undergraduate nursing students enrolled in the evidence-based nursing course in a fourth level program at the faculty of nursing, Mansoura University. All students who studied the course during the first semester of the academic year 2018-2019 were 180 students. All of them were invited to participate in the study, but only 95 of them agreed to participate in the FGD.

\subsection{Study Tool}

FGD guiding questions were used to encourage verbalization:

Q1. Describe your experience with studying evidencebased practice throughout the course of "Evidence-Based Nursing"?

Q2. What are the possibilities of the application of evidence-based practice in the nursing field?

Q3. What are the difficulties you faced in studying evidence-based practice course?

Q4. How do you describe the concept map as an educational method?

These questions of the FGD were translated from Arabic into English and vice versa to ensure the meaning consistency. To test the validity of the FGD guiding questions, a jury of five academic nursing staff members who have experience in qualitative research revised the questions. Moreover, the Arabic version of these questions was piloted on ten students before conducting the study. Questions were modified according to the findings of the pilot test and the comments of juries.

\section{Process of Study Implementation}

The "Evidence-Based Nursing" course is focused on enabling students to be skillful in implementing the five steps of evidence-based practice: formulating answerable questions, tracking the evidence, appraising the evidence, applying the evidence and evaluating the practice change.

An experienced team of teachers was assigned to teach the evidence-based nursing course. The allocated time of the course was three credit hours (1 credit hour for theoretical teaching and 2 credit hours for practical training). The time table of the course was 7 hours weekly throughout 12 weeks. Sessions of the course content is illustrated in Table 1. The theoretical part of each topic was presented in a one-hour interactive lecture followed by 12 hours of practical training (6 hours/ week). 
Table 1. Sessions of evidence-based nursing course

\begin{tabular}{|l|l|}
\hline Sessions. & Content \\
\hline $1^{\text {st }}$ week & $\begin{array}{l}\text { - Introduction to the concept, importance, and skills of evidence-based practice. } \\
\text { - Illustration and training of concept map. }\end{array}$ \\
\hline $2^{\text {nd }}$ and $3^{\text {rd }}$ weeks & Theoretical and practical training on "formulating answerable questions". \\
\hline $4^{\text {th }}$ and $5^{\text {th }}$ weeks & Theoretical and practical training on "tracking down the evidence". \\
\hline $6^{\text {th }}$ and $7^{\text {th }}$ weeks & Theoretical and practical training on "critically appraising evidence". \\
\hline $8^{\text {th }}$ and $9^{\text {th }}$ weeks & $\begin{array}{l}\text { Application of evidence and practical training on integrating research evidence and healthcare professionals' } \\
\text { experiences with patients' values and preferences. }\end{array}$ \\
\hline $10^{\text {th }}$ and $11^{\text {th }}$ weeks & Evaluating the practice change. \\
\hline $12^{\text {th }}$ week & Finalizing of the learning project. \\
\hline
\end{tabular}

The concept map was introduced through planned step-by-step instructions that highlighted the structure of the concept map, essential key concepts, linkages and its benefits for developing the knowledge and skills. Students were provided with a specially-prepared handout that included the definition of concept map, different uses, and examples of concept maps. The concept map was used along with other different teaching and learning methods that were used in teaching this course as interactive lectures, small group discussion, project-based learning, facilitated practice at the computer and simulated laboratories, facilitated practice in clinical placement, and self-study.

During the practical training, the students were divided into small groups; each group was composed of 6-7 students who were asked to select a clinical problem to apply the steps of evidence-based practice throughout their assigned project. Students formulated a well-defined clinical question/s by using PICO(T) format related to the selected clinical problem according to Leonardo, R. [31].

Computer laboratory training was used to train the students on tracking down evidence by searching different scientific databases in which the teachers explained and demonstrated an electronic search. Then, the students were asked to track down their intended evidence by hands-on search. The tracked down evidence was critically appraised by the appropriate critical appraisal tools. The researchers went around checking students' progress and gave instructions where necessary.

Field training time in primary healthcare units was allocated for assessing individuals and families' values/preferences regarding the proposed clinical decision that is related to the pre-defined clinical problems. Finally, the students concluded a clinical decision for the previously stated clinical problem based on the results of field assessment and findings of implementing the new evidence.

Through using the concept map, the students of each small group became able to generate a list of concepts for their selected clinical problem. Then, they integrated the clinical problem in a constructed map that showed their understanding of the concepts of evidence-based practice. The students were free to make connections among the concepts and labeled the lines with their own words. The teachers could gather meaningful information about the students' conceptual understanding and conceptual development through the analysis of the concepts and propositions in the student-constructed concept maps.

\subsection{Data collection}

Focus group discussions were conducted with the nursing students (ten sessions). Each session included 810 students and consumed 45-60 minutes. The total consuming time was 5.5 hours. The focus group discussions were conducted at a suitable time and an accessible venue. Each FGD was steered by the two researchers; one of them managed the FGD as a moderator and the other researcher worked in recording the discussion. The moderator started by presenting the aim of the FGD and proceeded by asking questions, while the other researcher recorded students' responses. The moderator asked questions in a free-flowing, interesting discussion, and probed for more details. The moderator assured that the discussion did not digress and tried to ensure that everyone has an input and that no one student dominates the discussion. The sessions of FGD continued until data saturation was reached at the point where no new data were being observed.

\subsection{Data Analysis}

Thematic analysis was used to explore the nursing students' experiences and views with studying evidencebased practice, the acquired skills, challenges and concept map as an educational method. The interview transcripts were analyzed to search for common themes, similarities, and/or variations among students' experiences and views. Data were coded, identified under categories and subcategories, and organized together under common themes. To boost the validity of the thematic analysis, three volunteer colleagues reviewed the findings to clarify the analysis in relation to emerging categories and themes [32].

\subsection{Ethical Consideration}

The proposal of this study was approved by the community health nursing departments' committee and the faculty research ethics committee. Informed oral consents from the students were obtained. The students were all informed that all the obtained information would be considered confidential and analyzed anonymously.

\section{Results}

Based on the findings of the content analysis, the study results are presented by qualitative data and illustrated in the following major themes as shown in Diagram 1. 


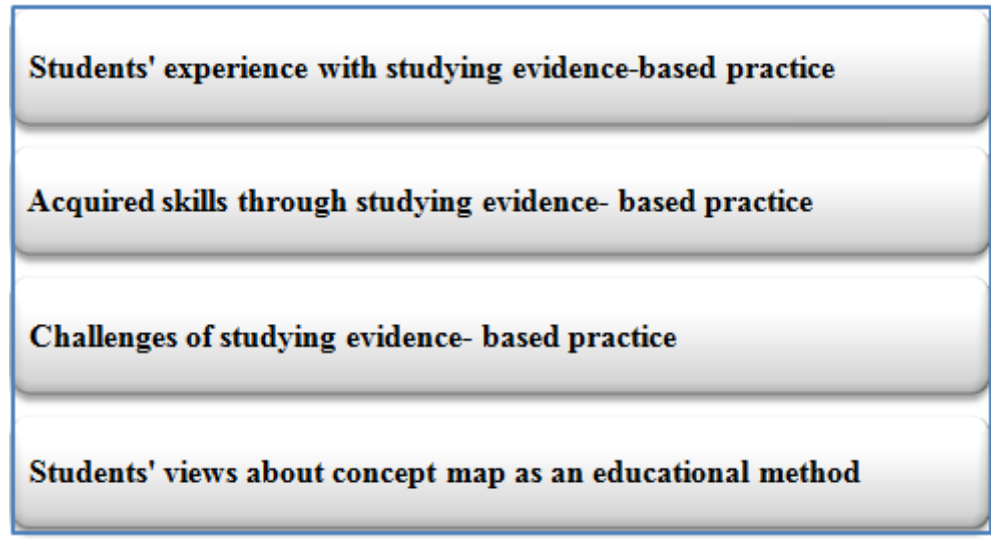

Diagram 1. Illustration of study themes

\section{Students' experience with studying evidence-based practice:}

Box 1, illustrates students' experience with studying evidence- based practice (EBP). Most of the students reported positive views about studying "EBP". Many students $(n=43)$ mentioned that EBP is a novel and beneficial approach for their future practice. Other students found the EBP was an interesting subject. Many students $(n=37)$ mentioned that EBP would be applied in all nursing specialties. They believed that EBP improves the quality of care, and they feel confident in providing evidence-based nursing care. An example of their narratives is as follows: FG 7 reported: "When I use EBP, I trust the delivered care to the patients", FG 3: "I recommend future application in clinical practice”, FG 1: "It was a beneficial course", FG 3: "The course has a future benefits", FG 6, FG7: "It was a new and an interesting experience”, FG 6: "The course was important for clinical practice". FG 18: "I had benefited from studying EBN course". FG 7: "It was a beneficial experience", FG 6: "It was beneficial for future practice", FG 8: "We like it and enjoyed studying".

Other students $(n=14)$ realized that EBP depends on understanding and application rather than recall. In this regard, FG 3 reported: "The course requires practical application not theory”. FG 7: “It depends on understanding not memorization”, FG 9: “An experience which needs understanding”. Moreover, other students ( $\mathrm{n}=$ 22) expressed their interest in studying EBP in the future, FG 3: "It will be beneficial to study EBN in more advanced level after graduation". FG 7, FG 11: "I had benefited from studying EBN course...so I will study it in the future”.

Box 1. Students' experience with studying evidence-based practice

- Novel and beneficial approach

- Interesting subject

- Applicable in all nursing specialties

- Improves the quality of care

- Depends on understanding and application

- Intentions to be studied in future

\section{2- Acquired skills through studying evidence- based practice:}

The acquired skills through studying EBP are summarized in Box 2, as described by the students.
Emphasis on the concept of self-learning was reported by some students $(\mathrm{n}=8)$. FG 2: "I became able to find information by myself”, FG 9: "After studying this course, I did not need to ask others for information... but I can reach it alone". Twenty-nine students reported that studying EBP provided them with the skill of identifying gaps in professional practice, tracking scientific research from valid scientific databases and search engines. FG 2: "The course taught us how to identify gaps in professional practice", FG 4: "The course taught us method of searching in trustful websites", FG 6: "I learned how to search on scientific databases in an objective way", FG 8: "I learned searching new databases in a valid way". Furthermore, eleven students stated that they acquired skills of critical appraisal. FG 3: "I learned how to appraise scientifically", FG 5: "I learned how to appraise a paper and select the best research", FG 7: "Criticize a paper and determine if it is valid or not".

Problem-solving and critical thinking skills were reported by 44 students. They also mentioned that EBP emphasized the involvement of patients in clinical decision-making that ensure the efficiency of the provided care. FG 3: "EBP helped in solving the problem by scientific and objective way", FG 2: "It increase the effectiveness of nursing care because of patients' involvement in deciding their management plan", FG 3: "It broadens thinking, increases ability of problem solving and provides a bulk of knowledge", FG 6: "It is a new approach for searching and solving problem-based on evidence", FG 8: "EBP helped me to determine the problem and solve it based on evidence", FG 10: "Identification of the steps of solving any problem in a scientific way", FG 5: "I became able to integrate different concepts together to find a solution".

Box 2. Acquired skills through studying evidence-based practice

- Strengthen skills of self-learning

- Acquired skill of identifying gaps in professional practice

- Acquired skills of tracking down scientific research

- Acquired skills of critical appraisal

- Strengthen skills of problem-solving and critical thinking skills

- Strengthen involvement of patients in clinical decision-making 


\section{3- Challenges of studying evidence- based practice:}

On contradictory, few challenges of studying EBP were mentioned in Box 3. Some students $(n=15)$ mentioned the inappropriate ratio of the students to the number of computers and staff members were challenging the learning process. The internet access sometimes was unstable, the allocated session time was inadequate as well as it was time-consuming to be studied. FG 1: "The number of students in the lab was too many", FG 2: "Few numbers of staff in relation to students' number", FG 4: "The staff number was little", FG 1: "The network sometimes was not available", FG 3: "Time was not enough", FG 2: "Time was limited", FG 4: "Searching required long time and efforts to find the required research", FG 8: "The course demands more time for studying and understanding".

Other students $(n=20)$ found EBP was difficult and few of them felt anxious at the beginning. FG 5: It was difficult especially at the start", FG 1: "It caused some anxiety and fear from it". In relation to the content of the EBP, few students (3 students) reported difficulties in searching and critical appraisal step of evidence-based practice. FG 1: "The appraisal step was the most difficult part", FG 7: "Searching on some databases was difficult".

Box 3. Challenges of studying evidence-based practice

- Insufficient resources

- Feeling anxious

- Difficulties in tracking down and critical appraisal of evidences

\section{4- Students' views about concept map as an educational method}

Box 4, illustrates students' views about using of concept map as educational method in teaching EBP. Most of the students $(n=60)$ stated that the concept map as an educational method facilitated the understanding of the concept of EBP through the integration of EBP's steps and summarization of the content. They mentioned also that using of concept map helped in retaining information, studying and preserving time. FG2: "Made evidence steps easy", FG 10: "It combined all things in one paper", FG 1: "It can be used for integration between the concepts/items", FG7: "It made the course integrated", FG 4: "It summarized the evidence content and topic", FG 10: "It summarized the topic and combined all concepts ", FG 3: "The diagram summarized the course". FG: 2 "It was as an illustrative visual presentation that helped to retain information", FG 19:"We did not forget any steps", FG8: "By using of concept map, I spent less time in studying”.

Other students $(n=10)$ reported that using of concept map grasped the attention of the audience, acquired presentation and communication skills and strengthen the self-learning competencies. FG7: "I learned how to learn by myself ", FG 8: "It made the topic presentation easy", FG 5:"It helped in presenting the step in an orderly way". Consequently, they felt self-confidence and acquired the skills of teamwork and problem-solving. FG9: "I became confident about myself”, FG6: “Concept map increased our spirit of teamwork and cooperation", FG 8: "I can respond to patients' questions and find the solution to their problems". On the other hand, some students $(n=21)$ described a few disadvantages of the concept map. They reported that it required computer skills, and it was difficult for them to construct it on the computer. They found concept map consumed a lot of efforts and time for designing it. FG1: "Concept map needed internet and computer skills", FG 2: "Concept map took much efforts".

Box 4. Students' views about concept map as an educational method
Advantages of concept map:
- Facilitates the understanding of EBP concept
- Summarizes and integrates the course content
- Grasps audience attention
- Acquires presentation and communication skills
- Strengthen the self-learning competencies
- Gives feelings of self-confidence
- Acquires skills of teamwork and problem-solving
Disadvantages of concept map:
- Requires computer skills
- Consumes efforts and time

\section{Discussion}

Embedding evidence-based practice (EBP) into nursing curricula became a mandatory issue to enable students to be competent healthcare professionals in the future. Studying EBP will build skills in using the most valid and recent research results in providing effective nursing care for individuals and communities [33]. Learning through a constructivist approach, active and participatory learning strategies are highly recommended for teaching EBP. These approaches make students actively productive participants and enhance critical thinking skills [34].

The concept map is one of the educational strategies that would facilitate the learning process of EBP by attaining the aim of active learning [35]. In Egypt, EBP is a novel subject in nursing education as well as using of concept map has a few studies concerned about. So, the use of qualitative research method which has several hallmarks and conducted in natural setting was adopted to explore in-depth the undergraduate nursing students' experience with EBP and concept map as an educational method.

To comprehend their experience with EBP and concept map, the current study indicated that most of the undergraduate nursing students showed positive views toward studying EBP and accepted the concept map as a novel educational strategy. Nursing students believed that EBP is a valid, objective and beneficial for their future practice. These points of view could imply that nursing students are ready to deliver evidence-based nursing care as revealed by Melnyk et al., [36] who indicated that nurses are ready for delivering evidence-based care in their institutions when they do value EBP. They thought that EBP improves the quality of care, and providing evidence-based nursing care made them more confident in their performance. Other researches confirmed the findings of the current study, in which nursing and medical students in Australia, Czech, and Nepal revealed positive views and attitude toward EBP. All of these studies reported that students enjoyed studying EBP and showed interests in practicing it in their professional carrier [37,38,39]. Conversely, these study findings 
contradict with a study reported that undergraduate nursing students experienced a lack of support and opportunity to practice EBP and also a lack of confidence in employing EBP independently [9].

Students of the present study indicated that they learned many skills through studying EBP. They became able to define clinical problems and to make a decision about patient care based on valid evidence by practicing the steps of EBP. They mentioned that EBP strengthen the concept of self-learning and skills of independence in recognizing variations in professional practice, in addition to acquiring problem-solving and critical thinking skills. These findings portrayed the willingness of nursing students in updating their knowledge and practice for the purpose of providing a high quality of care. The current figure is supported by many researches that concluded that nurses' perceptions of EBP were focused on professional growth, as well as expanding their knowledge base and skill for standardized healthcare [33,40,41,42,43,44]. Moreover, the current results were in agreement with Herliani et al. [45] who found that students gained skills of retrieving and appraising single empiric articles, as well as assessing the strength of the evidence.

However, based on their experience and self-awareness, the present study revealed some challenges faced the students in studying EBP. The students reported insufficient resources such as the number of available computers and allocated session time. They felt anxious at the beginning and found difficulties in searching and critical appraisal step of EBP. Other studies [39,46] also reported that insufficient time and resources were perceived as barriers of studying EBP.

Nursing students are interested in the educational strategies that assist in more long-lasting the knowledge they gain, and the more effectively they can explain. They are concerned with applying the gained knowledge in reality at different healthcare settings [47]. The current study findings revealed that most of the students assured that using concept maps in teaching EBP enabled them to recognize the concept of EBP and to connect EBP's steps to comprehend the content. They mentioned also that using of concept map helped them in retaining information, studying and preserving time. The same findings were reported in two systematic reviews and meta-analysis which indicated that concept maps were effective for knowledge retention and transformation [48]. In addition, another Iranian study confirmed the present results. It indicated that concept mapping method provided effective and meaningful EBP education [49].

In the student-centered approaches, learners actively participate in the process to acquire critical thinking, selfdirected learning, communication, and teamwork skills [50]. Moreover, other studies reported that concept map improves social communication skills, and enhance learning motivation and nursing students prefer and are satisfied with teaching methods that involve them actively in the learning tasks [51,52]. Self-learning was emphasized by some students in the current study as they stated that the concept map intensified their self-learning competencies and team-work skills. Students in the present study experienced self-confidence because they acquired presentation skills. They expressed that using of concept map grasp the attention of the audience, acquire presentation and communication skills. These findings would be interpreted in the highlight of many studies that concluded that concept map allowed students to be engaged in the learning process and improved their critical thinking [53,54,55].

Feeling of self-confidence among students of the current study might be attributed to the acquired skills of problem-solving as they mentioned. These reputations of concept map were reported by many researchers who viewed the concept map as an educational method produced visual conceptualization that enhancing the learning process and acquiring problem-solving skills. In addition, they found the concept map provides an enjoyable learning environment that permits students to express their own ideas and intellectual capabilities $[55,56,57,58]$. Difficulty in constructing the design of concept map and time-consuming were among the disadvantages the students encountered in concept map application which is agreed with [20,59].

\section{Conclusion}

Undergraduate nursing students showed positive views regarding EBP and concept map. They portrayed their interests in studying EBP and their intentions to apply it in their future career. Nursing students were enthusiastic to use the concept map in studying other scientific materials because it helped them in understanding the course content and retaining information. They found the concept map was very helpful in problem-solving.

\section{Recommendations}

The study recommended continuity of teaching EBP for undergraduate nursing students and embedding course of EBP in nursing curricula in post-graduate studies. Using of concept map in teaching all nursing academic courses especially community health nursing courses. Further researches are still needed for investigating interactive and clinically integrated teaching strategies that enhance nursing students' knowledge and skills in EBP. Other studies would be conducted to assess the impact of the concept map method on students' academic achievement in mastering EBP. The faculty would upgrade the computer laboratory, internet access to facilitate the implementation of educational activities.

\section{Acknowledgements}

We express our sincere gratitude to all the students who had enthusiastically participated in the study in spite of their tight academic schedule.

\section{Disclosure}

We pronounce that our work was not influenced by any monetary and personal associations improperly. 


\section{References}

[1] Younhee Kang, In-Suk Yang. (2016). Evidence-based nursing practice and its correlates among Korean nurses. Applied Nursing Research, 31, 46-51.

[2] Melissa V. Taylor, Beverly A. Priefer, Anna C. Alt-White. (2016). Evidence-based practice: Embracing integration. Nurs Outlook, 64, 575-582.

[3] María Ruzafa-Martínez, Lidón López-Iborra, David Armero Barranco, Antonio Jesús Ramos-Morcillo. (2016). Effectiveness of an evidence-based practice (EBP) course on the EBP competence of undergraduate nursing students: A quasi-experimental study. Nurse Education Today 38, 82-87.

[4] General Authority for Healthcare Accreditation \& Regulation (GAHAR), Egypt. National Safety Requirements (NSR) for Hospitals, 2019.

https://www.academia.edu/15580307/Egyptian_HealthCare_Accre ditation_Program_Standards_for_Hospitals_Foundation_Level_Se IfAssessment_Tool_2014_Ministry_of_Health_and_Population_ Minister_Office_Sector.

[5] Joint Commission International Accreditation Standards for Primary Care, $2^{\text {nd }}$ Edition 2019. Retrieved from https://www.jointcommission.org/standards_information/edition.a spx.

[6] Breimaier, H. E., Halfens, R. J., \& Lohrmann, C. (2011). Nurses' wishes, knowledge, attitudes and perceived barriers on implementing research findings into practice among graduate nurses in Austria. Journal of Clinical Nursing, 20(11-12), 1744-1756.

[7] Pereira, F., Pellaux, V., \& Verloo, H. (2018). Beliefs and implementation of evidence-based practice among community health nurses: A cross-sectional descriptive study. Journal of Clinical Nursing, 27(9-10), 2052-2061.

[8] Azmoude, E., Farkhondeh, F., Ahour, M., \& Kabirian, M. (2017) Knowledge, Practice and Self-Efficacy in Evidence-Based Practice among Midwives in East Iran. Sultan Qaboos University Medical Journal, 17(1)

[9] Ryan, E. J. (2016). Undergraduate nursing students' attitudes and use of research and evidence-based practice - an integrative literature review. Journal of Clinical Nursing, 25(11-12), 1548-1556.

[10] Sin, M., \& Bliquez, R. (2017). Teaching evidence based practice to undergraduate nursing students. Journal of Professional Nursing, 33(6), 447-451.

[11] Hung, H., Wang, Y., Feng, J., Wang, C., Lin, E. C., \& Chang, Y. (2018). Evidence-Based Practice Curriculum Development for Undergraduate Nursing Students. Journal of Nursing Research, 1.

[12] André, B., Aune, A. G., \& , J. A. (2016). Embedding evidencebased practice among nursing undergraduates: Results from a pilot study. Nurse Education in Practice, 18, 30-35.

[13] Llasus, L., Angosta, A. D., \& Clark, M. (2014). Graduating Baccalaureate Students' Evidence-Based Practice Knowledge, Readiness, and Implementation. Journal of Nursing Education, 53(9).

[14] Liou, S., Cheng, C., Tsai, H., \& Chang, C. (2013). Innovative Strategies for Teaching Nursing Research in Taiwan. Nursing Research, 62(5), 335-343.

[15] Horntvedt, M. T., Nordsteien, A., Fermann, T., \& Severinsson, E. (2018). Strategies for teaching evidence-based practice in nursing education: A thematic literature review. BMC Medical Education, 18(1).

[16] Schuster, P. M. (2000). Concept Mapping: Nurse Educator, 25(2), 76-81.

[17] Atay, S., \& Karabacak, Ü. (2012). Care plans using concept maps and their effects on the critical thinking dispositions of nursing students. International Journal of Nursing Practice, 18(3), 233-239.

[18] Bamidele, E., \& Oloyede, E. O. (2013). Comparative Effectiveness of Hierarchical, Flowchart and Spider Concept Mapping Strategies on Students' Performance in Chemistry. World Journal of Education, 3(1).

[19] Barrett, K. (2014). An Evaluation of the Use of Concept Maps in the Development of Critical Thinking in One Cohort of Preregistration Nursing Students. University of Ulster.
[20] Harrison, S., \& Gibbons, C. (2013). Nursing Student Perceptions of Concept Maps: From Theory to Practice. Nursing Education Perspectives, 34(6), 395-399.

[21] Evidence-Based Nursing: Rationale and Resources. (2004). Worldviews on Evidence-Based Nursing, 1(1), 69-75.

[22] Kohatsu, N., Robinson, J., \& Torner, J. (2004). Evidence-based public health. An evolving concept. American Journal of Preventive Medicine, 27(5), 417-421.

[23] Glasziou, P., Del, Mar. C., Salisbury, J. (2007). Evidence- Based Practice Workbook, $2^{\text {nd }}$ edition. Blackwell Publishing Ltd., Oxford, UK.

[24] Allen, J. D. (2012). Effects of concept mapping on meaningful learning and achievement in chemistry. Dissertation Abstracts International, 50(11):3542

[25] Rovira, C. (2016). Theoretical foundation and literature review of the study of concept maps using eye tracking methodology. El Profesional De La Información, 25(1), 59.

[26] Speicher, T.E., Bell, A., Kehrhahn, M., Casa, D.J. (2012). Casebased analogical reasoning: A pedagogical tool for promotion of clinical reasoning. Athl Train Educ J., 7(3): 129-136.

[27] Oliver, K. (2012). An investigation of concept mapping to improve the reading comprehension of science texts. Journal of Science Education and Technology, 18(5):1-18.

[28] Stiffler, D., \& Cullen, D. (2010). Evidence-based Practice for Nurse Practitioner Students: A Competency-based Teaching Framework. Journal of Professional Nursing, 26(5), 272-277.

[29] Barbour, R. S. (2005). Making sense of focus groups. Medical Education, 39(7), 742-750.

[30] LoBiondo-Wood, G., \& Haber, J. (2018). Nursing research: Methods and critical appraisal for evidence-based practice. St. Louis, MO: Elsevier.

[31] Leonardo, R. (2018). PICO: Model for Clinical Questions. Evid Based Med Pract, 3: 115.

[32] Alhojailan, M. I. (2012). Thematic Analysis: A Critical Review of Its Process and Evaluation. West East Journal of Social Sciences, 1(1).

[33] Belowska, J., Panczyk, M., Zarzeka, A., \& Gotlib, J. (2015) Knowledge and attitudes of nursing students towards evidencebased medicine and evidence-based nursing practice. Polish Journal of Public Health, 125(4), 201-204.

[34] Levin, R. F. (2010). Integrating Evidence-Based Practice with Educational Theory in Clinical Practice for Nurse Practitioners: Bridging the Theory Practice Gap. Research and Theory for Nursing Practice, 24(4), 213-216.

[35] Bauman, A. (2018). Concept Maps: Active Learning Assessmen Tool in a Strategic Management Capstone Class. College Teaching, 66(4), 213-221.

[36] Melnyk, B. M., Fineout-Overholt, E., Gallagher-Ford, L., \& Kaplan, L. (2012). The State of Evidence-Based Practice in US Nurses. JONA: The Journal of Nursing Administration, 42(9), 410-417.

[37] Ilic, D., \& Forbes, K. (2010). Undergraduate medical studen perceptions and use of Evidence Based Medicine: A qualitative study. BMC Medical Education, 10(1).

[38] Zeleníková, R., \& Jarošová, D. (2014). Perception of the effectiveness of evidence-based practice courses by Czech nursing and midwifery students. Central European Journal of Nursing and Midwifery, 5(4), 169-175.

[39] Karki, S., Acharya, R., Budhwani, H., Shrestha, P., Chalise, P., Shrestha, U., Wilson, L. (2017). Perceptions and Attitudes towards Evidence Based Practice among Nurses and Nursing Students in Nepal. Kathmandu University Medical Journal, 13(4), 308-315.

[40] Delaney, C., \& Piscopo, B. (2004). RN-BSN Programs. Journal for Nurses in Staff Development (JNSD), 20(4), 157-161.

[41] Ozsoy, S. A., \& Ardahan, M. (2008). Research on knowledge sources used in nursing practices. Nurse Education Today, 28(5), 602-609.

[42] Neda, M., Soodabeh, J., Azadeh, J., \& Naser, B. (2012). Nursing faculties' knowledge and attitude on evidence-based practice. Iran J Nurs Midwifery Res, 17(7): 506-511.

[43] Florin, J., Ehrenberg, A., Wallin, L., \& Gustavsson, P. (2011) Educational support for research utilization and capability beliefs regarding evidence-based practice skills: A national survey of senior nursing students. Journal of Advanced Nursing, 68(4), 888-897. 
[44] Jakubec, S. L., \& Astle, B. J. (2012). Students Connecting Critical Appraisal to Evidence-Based Practice: A Teaching-Learning Activity for Research Literacy. Journal of Nursing Education, 52(1), 56-58.

[45] Herliani, Y. K., Harun, H., Setyawati, A., \& Ibrahim, K. (2018). Self-Efficacy and the Competency of Nursing Students toward the Implementation of Evidence-Based Practice. Journal Ners, 13(1), 50.

[46] Cepanec, D., Clarke, D., Plohman, J., \& Gerard, J. (2013). Engaging Undergraduate Nursing Students in Research: The Students' Experience of a Summer Internship Program Pilot Project. Journal of Nursing Education, 52(8), 466-469.

[47] Wilgis, M., \& Mcconnell, J. (2013). Concept Mapping: An Educational Strategy to Improve Graduate Nurses' Critical Thinking Skills during a Hospital Orientation Program. The Journal of Continuing Education in Nursing, 39(3), 119-126.

[48] Nesbit, J. C., \& Adesope, O. O. (2006). Learning With Concept and Knowledge Maps: A Meta-Analysis. Review of Educational Research, 76(3), 413-448.

[49] Saeidifard, F., Heidari, K., Foroughi, M., \& Soltani, A. (2014) Concept mapping as a method to teach an evidence-based educated medical topic: A comparative study in medical students. Journal of Diabetes \& Metabolic Disorders, 13(1).

[50] Darvish, G. F., \& Roudbari, M. (2012). Teaching styles of faculty members in schools affiliated with Iran University of Medical Sciences. Iran J Med Educ, 11: 917-925.

[51] Kwon, S. Y., \& Cifuentes, L. (2009). The comparative effect of individually-constructed vs. collaboratively-constructed computerbased concept maps. Computers \& Education, 52(2), 365-375.
[52] Hajbaghery MA, \& Afazel MR. (2011). A comparison of the effects of instructional methods on satisfaction, anxiety and learning of nursing students. Future Med Educ J.; 4:11-15.

[53] Moahmed, H. F. (2013). Concept Mapping in Clinical Nursing: A Meaningful Learning. Life Science Journal, 10(12): 1037-1038.

[54] Carter-Templeton, H., Fitzgerald, K. S., \& Carter, M. (2016). Application of Concept Mapping as a Visual Thinking Strategy in an Asynchronous Online Graduate Informatics Course. CIN: Computers, Informatics, Nursing, 34(8), 331-335.

[55] El-Hay, S. A., Mezayen, S. E., \& Ahmed, R. E. (2018). Effect of concept mapping on problem solving skills, competence in clinical setting and knowledge among undergraduate nursing students. Journal of Nursing Education and Practice, 8(8), 34.

[56] Harrison, S., \& Gibbons, C. (2013). Nursing Student Perceptions of Concept Maps: From Theory to Practice. Nursing Education Perspectives, 34(6), 395-399.

[57] Morteza, G., Mir, H. A., Mohammad, N-B., Reza, Piri., Hakimeh, Hazrati., \& Saber,Azami-Aghdash. (2014). Using Concept Maps for Nursing Education in Iran: A Systematic Review. Res Dev Med Educ, 3(1), 67-72.

[58] Rahnama, F., \& Mardani-Hamooleh, M. (2017). Iranian Nursing Students' Perceptions Regarding Use of Concept Mapping: A Content Analysis. Research and Development in Medical Education,6(1), 45-50.

[59] Nirmala, T., \& Shakuntala, BS. (2011). Concept Mapping-an Effective Tool to Promote Critical Thinking Skills among Nurses. Nujhs. 1(4):2249-7110.

(C) The Author(s) 2019. This article is an open access article distributed under the terms and conditions of the Creative Commons Attribution (CC BY) license (http://creativecommons.org/licenses/by/4.0/). 